\title{
Sodium cromoglycate and doxantrazole are oxygen radical scavengers
}

\author{
G. Sadeghi-Hashjin, F.P. Nijkamp, P.A.J. Henricks, G. Folkerts
}

\begin{abstract}
Sodium cromoglycate and doxantrazole are oxygen radical scavengers. G. SadeghiHashjin, F.P. Nijkamp, P.A.J. Henricks, G. Folkerts. C) ERS Journals Ltd 2002.

ABSTRACT: The effects of two mast cell stabilisers, sodium cromoglycate (SCG) and doxantrazole, on the formation of reactive oxygen species (ROS) were studied. Guineapig alveolar macrophages (AMs) generated lucigenin-dependent chemiluminescence (LDCL). This was increased when the cells were stimulated by phorbol myristate acetate (PMA) or zymosan (by $133 \%$ and $464 \%$, respectively, in total LDCL over $60 \mathrm{~min})$. SCG decreased PMA-induced LDCL at higher concentrations $(10 \mathrm{mM}$, by $55 \%$ ) than doxantrazole ( $1 \mathrm{mM}$, by $75 \%$ ). SCG decreased radical production by AMs in response to zymosan in a concentration-dependent manner by $\leqslant 72 \%$. Doxantrazole (0.1-1 mM) diminished total LDCL by $30-80 \%$. In addition, glucose oxidase led to LDCL generation when incubated with glucose in a cell-free medium. This was inhibited by $47-83 \%$ in the presence of SCG or doxantrazole. SCG and doxantrazole inhibited the hydrogen peroxide- and peroxynitrite-induced LDCL by $\leqslant 92 \%$. Moreover, these drugs slightly increased the survival rate of the AMs.

It is concluded that doxantrazole- and sodium cromoglycate-inhibited lucigenindependent chemiluminescence production by guinea-pig alveolar macrophages is due to a direct scavenging effect on reactive oxygen species. Doxantrazole is $\sim 10$-times more potent. Mast cell stabilisers may be effective in allergic asthma not only by preventing the allergen-induced mediator release, but also by preventing radical-induced lung damage. Eur Respir J 2002; 20: 867-872.
\end{abstract}

Dept of Pharmacology and Pathophysiology, Utrecht Institute for Pharmaceutical Sciences, Utrecht University, Utrecht, the Netherlands.

Correspondence: G. Sadeghi-Hashjin Dept of Veterinary Basic Sciences Urmia University PO Box 641

Urmia

Iran

Fax: 984413443442

E-mail: g.sadeghi@mail.urmia.ac.ir

Keywords: Alveolar macrophages chemiluminescence

doxantrazole

oxygen radicals

sodium cromoglycate

Received: January 192002

Accepted after revision: May 92002
Sodium cromoglycate (SCG) is used in asthma therapy, although its role in treating the underlying pathophysiology remains controversial [1]. It is known that this drug stabilises the mast cell membrane, thereby inhibiting mediator release [2]. Evidence from previous publications suggests that there are some other mechanisms of actions of SCG in addition to its known anti-allergic properties. 1) The early asthmatic reaction (EAR) was not affected after inhalation of SCG in an ovalbumin model of airway hyperresponsiveness in the guinea pig, but the late asthmatic reaction (LAR) was significantly inhibited [3]. 2) SCG reduced injury on the irradiated side of rat lung [4]. 3) SCG is effective against interleukin-5-induced pulmonary inflammation in the guinea pig, particularly the desquamation of bronchial epithelial cells [5]. 4) SCG inhibits the expression of adhesion molecules and decreases the number of inflammatory cells in the airways of asthmatic patients [6].

The respiratory burst, a characteristic response of stimulated granulocytes and macrophages [7], leads to the formation of reactive oxygen species (ROS), which can kill microorganisms and may cause tissue damage [8]. ROS is generated by activated phagocytes and damaged mammalian cells [9]. Superoxide anion, an oxygen-centred radical, is an oxidation-reduction reagent capable of either oxidation to molecular oxygen or reduction to hydrogen peroxide [10].
Spontaneous production of this radical has been shown at sites of antigen challenge in allergic subjects and it contributes to the pathogenesis of airway injury associated with allergic inflammation [11]. Hydrogen peroxide, another ROS, damages ciliated epithelial cells and produces hyperresponsiveness of human isolated peripheral airways [12]. The current authors have shown that airway hyperresponsiveness is also induced when the guinea-pig isolated trachea is subjected to pyrogallol, a superoxide-generating substance [13]. Peroxynitrite is a potent cytotoxic anion, which is produced from interaction between nitric oxide and superoxide. It is produced by a number of inflammatory cells and may play a crucial role in the pathophysiology of airway disease [14]. Exogenously administered peroxynitrite mimics some inflammatory conditions in the respiratory tract, such as hyperresponsiveness to histamine and methacholine, epithelial damage, eosinophil destruction and the release of major basic protein in isolated perfused guinea-pig trachea, and a long-lasting airway hyperresponsiveness in anaesthetised animals [15].

The effect of SCG on alveolar macrophages (AMs) has not been studied extensively [16]. In the present study, the actions of SCG (a stabiliser of connective tissue mast cells) and doxantrazole (a new stabiliser of mucosal and connective tissue mast cells) on the production of ROS by guinea-pig AMs 
were investigated. ROS production was measured via emission of lucigenin-dependent chemiluminescence (LDCL). In addition, the effects of SCG and doxantrazole on LDCL produced by glucose oxidase/glucose interaction were also studied, via hydrogen peroxide $\left(\mathrm{H}_{2} \mathrm{O}_{2}\right)$ and peroxynitrite $\left(\mathrm{ONOO}^{-}\right)$in cell-free solutions. The aim of the study was to determine the possible interactions of these substances with the generation of ROS and, possibly, the mechanism involved.

\section{Materials and methods}

\section{Animals}

Specified pathogen-free guinea pigs (400-500 g, male Dunkin Hartley; Harlan Olac Ltd, Bicester, UK) were housed under controlled conditions. Water and commercial chow were allowed ad libitum. The guinea pigs were free from respiratory infections, as assessed by the health-monitoring quality control report by Harlan Olac Ltd and by histological examination. Guinea pigs were killed with an overdose of pentobarbital sodium (Euthesate $\mathrm{R}, 0.8 \mathrm{~g} \cdot \mathrm{kg}$ body weight $^{-1}$ i.p.; Apharmo bv, Arnhem, the Netherlands).

\section{Bronchoalveolar lavage and macrophage isolation procedure}

Bronchoalveolar lavages (BAL) were performed on the sacrificed animals as follows: the trachea was trimmed from the surrounding connective tissue and a small incision was made to insert a cannula into the trachea; the lungs were filled in situ with $15 \mathrm{~mL}$ prewarmed saline under a pressure of $30 \mathrm{cmH}_{2} \mathrm{O}$; fluid was withdrawn from the lungs after gentle massage for $60 \mathrm{~s}$ and saved; lavage continued and a centrifuge tube $(50 \mathrm{~mL})$ was filled for each guinea-pig. After lavage, the tubes were centrifuged at $500 \times g$ and $4{ }^{\circ} \mathrm{C}$ for $10 \mathrm{~min}$. The supernatant solution was discarded and the pellet was preserved. The cell pellet was resuspended in $15 \mathrm{~mL}$ of ice-cold medium (Roswell Park Memorial Hospital (RPMI) with 10\% foetal calf serum; Gibco, Grand Island, UK) and then gently transferred into another tube on top of a similar volume of Ficoll-Paque (Pharmacia Biotech AB, Uppsala, Sweden). Two separate layers were distinguishable. The tubes were centrifuged at $1,000 \times g$ and $4{ }^{\circ} \mathrm{C}$ for $20 \mathrm{~min}$. The interphase was isolated and its volume was adjusted to $15 \mathrm{~mL}$ with RPMI and centrifuged at $500 \times g$ and $4^{\circ} \mathrm{C}$ for $10 \mathrm{~min}$, this was then repeated. The BAL cells were stained with Türk solution (Merck, Darmstadt, Germany) and counted in a Bürker-Türk bright-line counting chamber (Glaswarenfabrik Karl Hecht KG, Sondheim, Germany). For differentiation, cells were spun on microscope slides at $45 \times g$ for $5 \mathrm{~min}$, fixed and stained

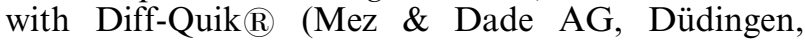
Switzerland). Differential counts were performed under oil immersion microscopy. The final cell suspension consisted of $99 \%$ macrophages.

\section{Lucigenin-dependent chemiluminescence emission}

LDCL production was measured with a LKB-1251 Luminometer (LKB Wallac, Turku, Finland). Cell suspensions containing $3 \times 10^{5}$ AMs were placed in luminometer cuvettes containing lucigenin $(50 \mu \mathrm{L}$; Sigma, St Louis, MO, USA), Zymosan A (100 $\mu \mathrm{L}$; Sigma) or phorbol myristate acetate (PMA, $50 \mu \mathrm{L}$; Sigma), in a final volume of $0.5 \mathrm{~mL}$ Krebs buffer. Lucigenin, a chemiluminescence indicator, was used at a final concentration of $500 \mu \mathrm{M}$. Opsonised Zymosan and PMA were used as cellular stimulants at final concentrations of $2.5 \mathrm{mg} \cdot \mathrm{mL}^{-1}$ and $0.16 \mu \mathrm{M}$, respectively. When the effects of SCG (Sigma) or doxantrazole (Sigma) on the generation of LDCL by the AMs were studied, $50 \mu \mathrm{L}$ of a 10 -fold concentrated solution of each compound was used in place of an equal volume of Krebs buffer. LDCL was measured over a 60-min time period. LCDL was also generated in a cell-free solution, using glucose oxidase $\left(0.1-100 \mathrm{U} \cdot \mathrm{mL}^{-1}\right.$; Sigma) plus glucose $(8.3 \mathrm{mM})$, hydrogen peroxide $(0.3-30 \mathrm{mM})$ and peroxynitrite (0.001-10 mM). Effects of superoxide dismutase (SOD) $\left(100 \mathrm{U} \cdot \mathrm{mL}^{-1}\right.$; Sigma), catalase $\left(100 \mathrm{U} \cdot \mathrm{mL}^{-1}\right.$; Sigma), SCG (1-10 $\mathrm{mM})$ and doxantrazole (0.1$1 \mathrm{mM}$ ) on the emission of LDCL were studied over $30 \mathrm{~min}$. The integrated response was determined with PC software supplied with the luminometer. Data are presented as peak LDCL $(\mathrm{mV})$ as well as the area under the curve (AUC) over 60 or $30 \mathrm{~min}(\mathrm{mV} \times \mathrm{min})$. LDCL generation was measured at $37^{\circ} \mathrm{C}$ in all experiments.

\section{Statistical analysis}

The peak $(\mathrm{mV})$ or AUC $(\mathrm{mV} \times \mathrm{min})$ of generated LDCL by individual treatment groups were averaged and expressed as means \pm SEM. The results of each set of experiments were evaluated by one-way analysis of variance (ANOVA). Where the level of significance was achieved by one-way analysis, post-ANOVA comparison of means was performed by using the Bonferroni t-test. All p-values $<0.05$ were considered to reflect a statistically significant difference.

\section{Results}

Lucigenin-dependent chemiluminescence production by alveolar macrophages

Nonstimulated BAL cells generated LDCL with a peak of $137 \pm 34 \mathrm{mV}$ and AUC of $3,564 \pm 228 \mathrm{mV} \times$ 60 min. PMA-treated cells generated more radicals, as identified by a $70 \%$ increase in the peak LDCL $(p<0.05)$ and a $133 \%$ increase in total LDCL in 60 min $(\mathrm{p}<0.01)$. Zymosan increased the basal peak by $155 \% \quad(p<0.01)$ and AUC by $464 \% \quad(p<0.001)$. Incubation of the cells with SOD diminished the peak by $\leqslant 79 \%$ and the AUC by $\leqslant 69 \%(\mathrm{p}<0.001)$.

After the AMs were incubated in the buffer for $1 \mathrm{~h}$ at $37^{\circ} \mathrm{C}, 40.3 \pm 10.2 \%$ of the cells were alive, as shown by trypan blue exclusion assay. Surprisingly, SCG 
(1-10 $\mathrm{mM})$ and doxantrazole $(0.1-1 \mathrm{mM})$ enhanced the survival rate by $\leqslant 65 \%$, although this did not reach the level of statistical significance.

SCG decreased PMA-induced LDCL at high concentrations $\quad(3.3-10 \mathrm{mM})$ by $\leqslant 55 \% \quad$ (fig. 1a). PMA-induced LDCL was reduced by doxantrazole (0.33-1 mM) by 23-75\% (fig. 2a). However, none of these changes reached the level of statistical significance.

SCG decreased radical production by AMs in response to zymosan in a concentration-dependent manner by $\leqslant 72 \%$. The effect was significant with 0.33 and $10 \mathrm{mM}$ (fig. 1b). Doxantrazole (0.1-1 mM) diminished the total LDCL by $30-80 \%$ (fig. $2 \mathrm{~b}$ ) in a concentration-dependent manner.

Lucigenin-dependent chemiluminescence generation by oxygen reactive species

Glucose oxidase $\left(10 \mathrm{U} \cdot \mathrm{mL}^{-1}\right)$ produced the highest intensity of LDCL when reacted with glucose for $30 \mathrm{~min}$ in a cell-free solution (data not shown). Total LDCL was inhibited by $>96 \%$ when SOD
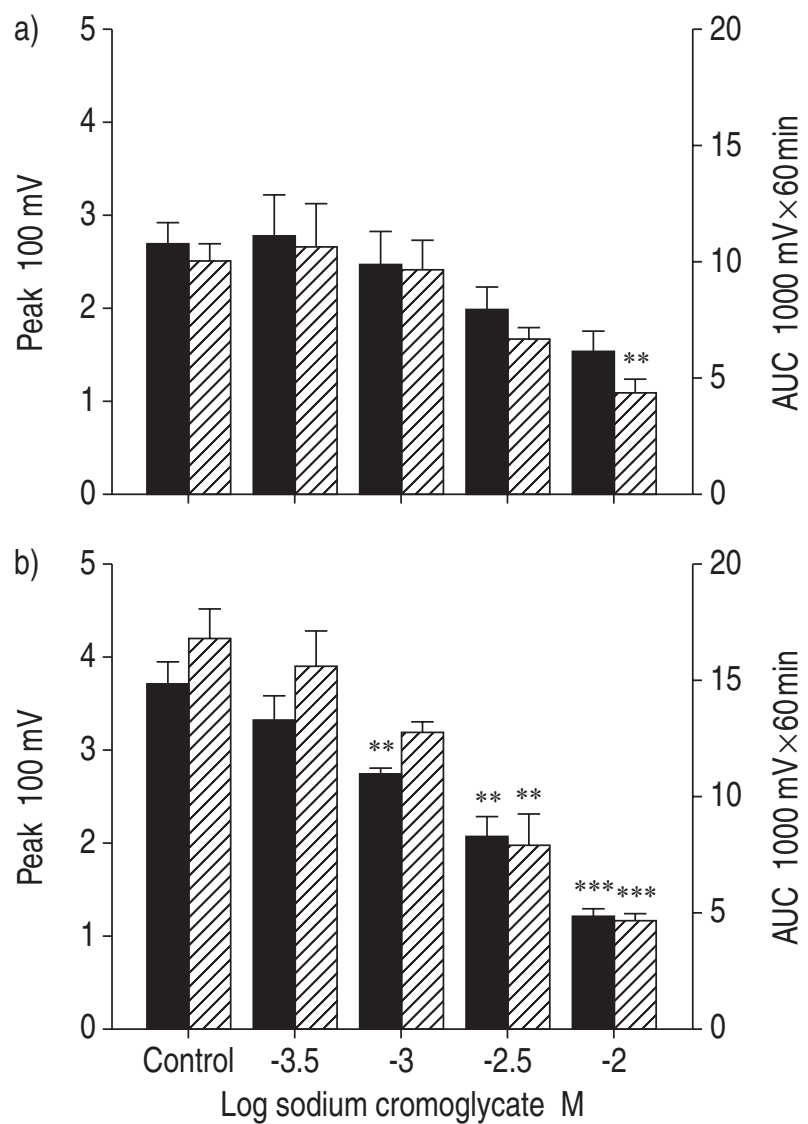

Fig. 1.-Lucigenin-dependent chemiluminescence (LDCL) emission from isolated guinea-pig alveolar macrophages $\left(3 \times 10^{5}\right.$ cells $)$ stimulated by either a) phorbol myristate acetate or b) zymosan A. The cells were co-incubated with sodium cromoglycate (SCG). Peak $(\boldsymbol{\square})$ and total $(\mathbb{Z})$ LDCL production by the cells over $60 \mathrm{~min}$ are shown. SCG was found to inhibit the LDCL emission in a concentration-dependent fashion. $\mathrm{n}=4$. **: $\mathrm{p}<0.01 ; * * *$ : $\mathrm{p}<0.001$, compared to the corresponding control group. AUC: area under curve.
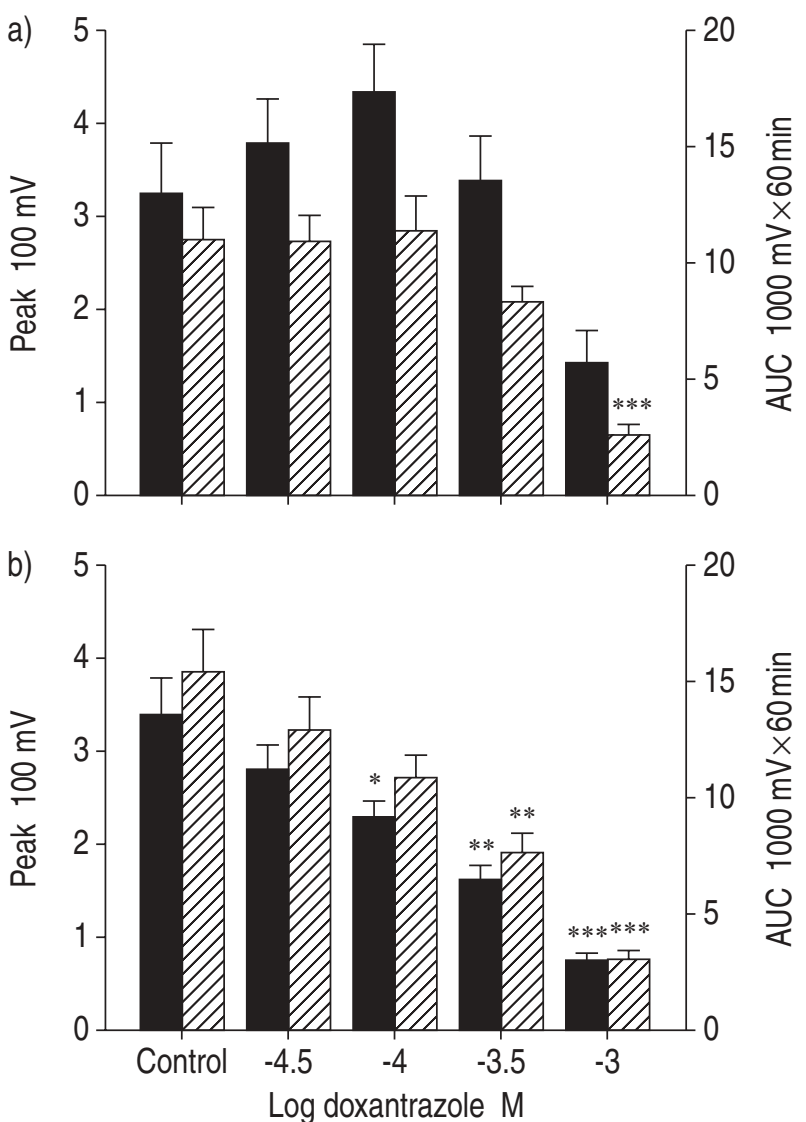

Fig. 2.-Lucigenin-dependent chemiluminescence (LDCL) emission from isolated guinea pig alveolar macrophages $\left(3 \times 10^{5}\right.$ cells $)$, stimulated by either a) phorbol myristate acetate or b) zymosan A. The cells were co-incubated with doxantrazole. Peak $(\mathbf{a})$ and total $(\mathscr{C})$ LDCL production by the cells over $60 \mathrm{~min}$ is shown. Doxantrazole was found to inhibit the LDCL emission in a concentration-dependent fashion. $\mathrm{n}=4$. *: $\mathrm{p}<0.05 ; * *: \mathrm{p}<0.01 ; * * *: \mathrm{p}<0.001$, compared to the corresponding control group. AUC: area under curve.

$\left(100 \mathrm{U} \cdot \mathrm{mL}^{-1}\right)$ was added to the reaction mixture, whereas catalase had no effect (fig. 3a). This suggests that superoxide anion has an exclusive role in the reaction (fig. 3a). Total LDCL was inhibited by $47-83 \%$ in a concentration-dependent fashion when SCG (1-10 mM) was added to the mixture (fig. 4a). Doxantrazole $(0.1-1 \mathrm{mM})$ was similarly reduced total LDCL by $76-88 \%$ (fig. $4 \mathrm{a}$ ).

Hydrogen peroxide $(0.3-30 \mathrm{mM})$ led to the generation of LDCL at all concentrations (data not shown). However, $10 \mathrm{mM}$ of this agent was utilised in the remaining experiments as maximal light emission was achieved at this concentration. LDCL was entirely abolished by catalase but not by SOD (fig. 3b). SCG $(10 \mathrm{mM})$ and doxantrazole $(1 \mathrm{mM})$ inhibited the effect of hydrogen peroxide by $92 \%$ (fig. 4 b).

Peroxynitrite-induced LDCL was detectable at $0.1 \mathrm{mM}$, and at higher concentrations the intensity of the LDCL was above the sensitivity range of the chemiluminometer (data not shown). Surprisingly, SOD augmented LDCL induced by peroxynitrite by $91 \%$, whereas catalase reduced it by $80 \%$ (fig. 3c). SCG and doxantrazole inhibited the effect of peroxynitrite by $\leqslant 89 \%$ and $73 \%$, respectively (fig. $4 \mathrm{c}$ ). 

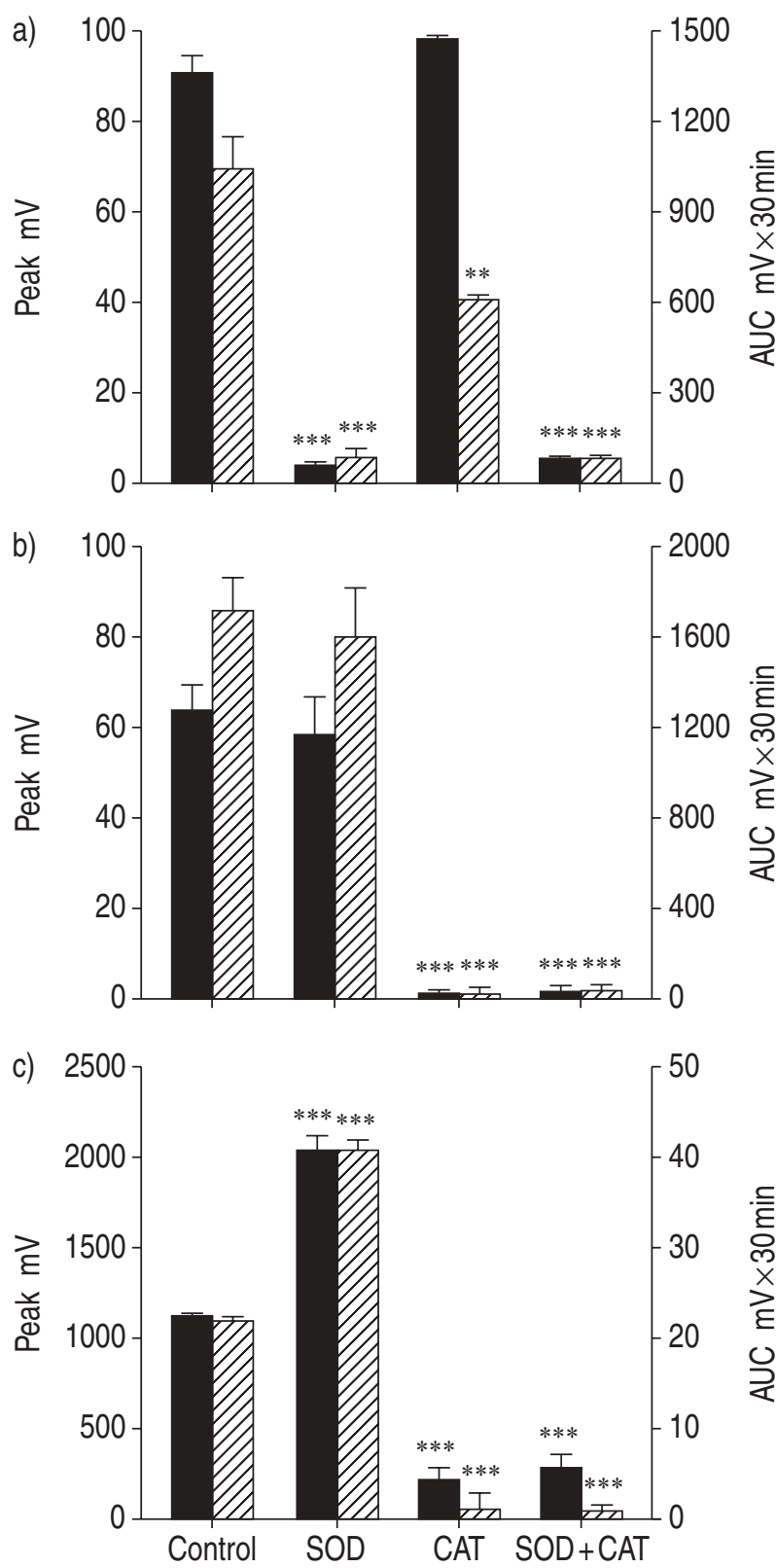

Fig. 3. - Lucigenin-dependent chemiluminescence (LDCL) emission by a) catalytic reaction between glucose $(0.8 \mathrm{mM})$ and glucose oxidase $\left.\left(\mathrm{GO} ; 10 \mathrm{U} \cdot \mathrm{mL}^{-1}\right), \mathrm{b}\right)$ hydrogen peroxide $(10 \mathrm{mM})$, and $\left.\mathrm{c}\right)$ peroxynitrite $(0.1 \mathrm{mM})$. The effects of $100 \mathrm{U} \cdot \mathrm{mL}^{-1}$ of superoxide dismutase (SOD) and/or catalase (Cat) on light emission were investigated. Peak ( $)$ and total $(\mathbb{Z})$ LDCL production by the cells over $30 \mathrm{~min}$ is shown. SOD blocked the LDCL generated by $\mathrm{GO} /$ glucose but not by hydrogen peroxide, while increasing that of peroxynitrite. Cat inhibited light emission by hydrogen peroxide and peroxynitrite but showed weaker influence on light emission by $\mathrm{GO} /$ glucose reaction. All experiments were performed in triplicate. $* *: \mathrm{p}<0.01 ; * * *: \mathrm{p}<0.001$, compared to the corresponding control. AUC: area under curve.

\section{Discussion}

AMs isolated from guinea pigs produced LDCL upon stimulation with a particulate or a soluble stimulus. This was reduced when mast cell stabilisers (SCG or doxantrazole) were added to the incubation buffer. Further experiments suggested that these substances
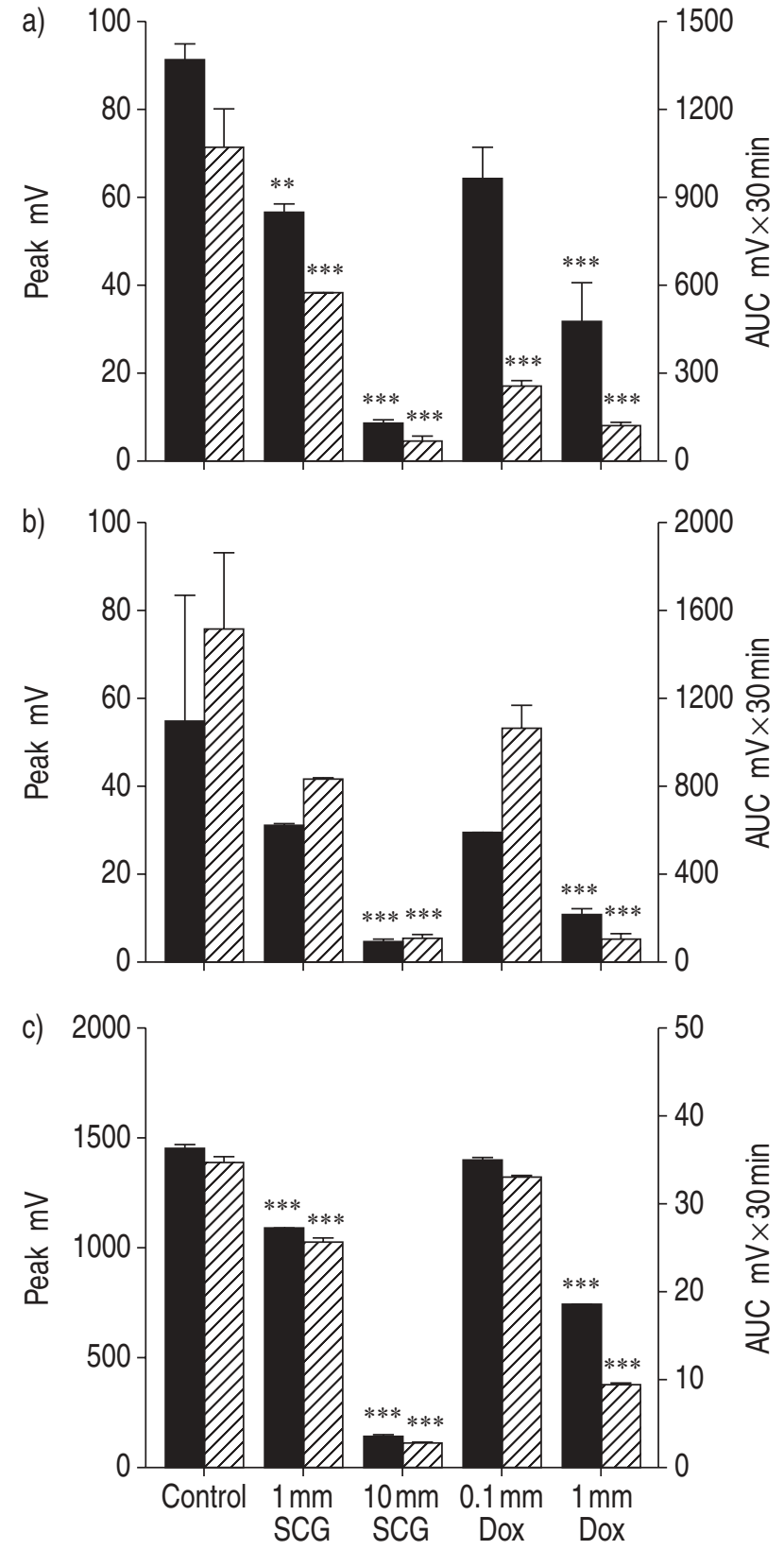

Fig. 4. - Lucigenin-dependent chemiluminescence (LDCL) emission by a) catalytic reaction between glucose $(0.8 \mathrm{mM})$ and glucose oxidase $\left.\left(\mathrm{GO} ; 10 \mathrm{U} \cdot \mathrm{mL}^{-1}\right), \mathrm{b}\right)$ hydrogen peroxide $(10 \mathrm{mM})$, and $\left.\mathrm{c}\right)$ peroxynitrite $(0.1 \mathrm{mM})$. The effects of sodium cromoglycate (SCG) (1-10 mM) and doxantrazole (Dox) (0.1-1 mM) on light emission were investigated. Peak (ם) and total $(\mathbb{G})$ LDCL production by the cells over $30 \mathrm{~min}$ is shown. SCG and Dox inhibited light emission in all treatment protocols. All experiments were performed in triplicate. **: $\mathrm{p}<0.01 ; * * *: \mathrm{p}<0.001$, compared to the corresponding control. AUC: area under curve.

are scavengers of ROS, such as superoxide and hydrogen peroxide, as well as peroxynitrite. In addition, these drugs slightly increased the survival rate of the cells in a concentration-dependent manner.

Superoxide anion is an important ROS generated by several metabolic processes, of which xanthine oxidase, reduced nicotinomide adenine dinucleotide phosphate (NADPH) oxidase, and P450 monooxygenase systems are the most important [17-20]. 
In the respiratory system, superoxide is produced by a variety of inflammatory cells [21-22] and it may be involved in the pathophysiology of respiratory disorders. Radical production by cells is characterised by the emission of chemiluminescence [23] and the chemiluminescence amplifier lucigenin is often used to increase the sensitivity to detect radicals [24].

The present study indicated a mechanism of action for two mast cell stabilisers in the respiratory tract that has not been previously identified. There is evidence in the literature that mast cell stabilisers have actions in other organs that are not related to their anti-allergic properties. For example, doxantrazole inhibited normal intestinal motility in the rat via an anti-cholinergic effect [25]. Doxantrazole inhibited the ovalbumin-induced increase in ion transport in the jejunal [26] and tracheal [27] mucosa from sensitised rats in vitro. Doxantrazole was more potent than SCG. In addition, antigen-induced contraction in the rat jejunal circular smooth muscle was inhibited by doxantrazole, but not by SCG [28]. It seems that doxantrazole has a higher overall potency, since it was also 10 -times more potent than SCG in scavenging free radicals in the present study. There are few reports regarding the effects of SCG on macrophages. This agent may enhance the capacity of rat peritoneal macrophages to bind sheep erythrocytes [29]. Interestingly, a very recent study demonstrated that a number of anti-asthma drugs, including SCG, reduce superoxide release from human eosinophils [30]. However, in this study, SCG was able to act at much lower concentrations incapable of exerting any scavenging effect in the current study. The concentrations needed to affect the LDCL were indeed high for both SCG (at least $1 \mathrm{mM}$ ) and doxantrazole (at least $0.1 \mathrm{mM}$ ). However, these concentrations might be clinically relevant in cases where mast cell stabilisers are administered repeatedly as aerosol to patients with asthma or allergic rhinitis, as local administration is likely to result in high concentrations of these agents.

In conclusion, sodium cromoglycate and doxantrazole show nonspecific antioxidant properties, not only against reactive oxygen species (such as superoxide and hydrogen peroxide) but also against peroxynitrite. Therefore, mast cell stabilisers may be effective in asthmatic patients not only by preventing the allergeninduced mediator release, but also by preventing airway tissue damage caused by reactive oxygen species during inflammatory processes. Alternatively, radical scavenging may be partly responsible for stabilisation of mast cells by sodium cromoglycate and doxantrazole. However, further studies are required.

Acknowledgement. The authors would like to thank I. van Ark and T. Muis for their technical assistance in this study.

\section{References}

1. Pueringer RJ, Hunninghake GW. Inflammation and airway reactivity in asthma. Am J Med 1992; 92: 32s38 s.
2. Neffen HE. Pharmaco-prevention of bronchial asthma using membrane stabilisers and asthma mortality. Rev Alerg Mex 1990; 37: 155-163.

3. Sugasawa T, Imanishi N, Morooka S. Effect of the selective PAF antagonist SM-10661 on an asthmatic model. 2. Effect on antigen-induced dual asthmatic response and infiltration of leukocytes into airways in actively sensitised conscious guinea pigs. Lipids 1991; 26: 1305-1309.

4. Graham MM, Evans ML, Dahlen DD, Mahler PA, Rasey JS. Pharmacological alteration of the lung vascular response to radiation. Intl J Radiat Oncol Biol Phys 1990; 19: 329-339.

5. Iwama $T$, Nagai $H$, Suda $H$, Tsuruoka N, Koda A. Effect of murine recombinant interleukin-5 on the cell population in guinea-pig airways. $\mathrm{Br} J$ Pharmacol 1992; 105: 19-22.

6. Hoshino M, Nakamura Y. The effect of disodium cromoglycate (DSCG) on infiltration of inflammatory cells into bronchial mucosa and on expression of adhesion molecules in asthmatics. Arerugi 1995; 44 : 593-601.

7. Baggiolini M, Wymann MP. Turning on the respiratory burst. Trends Biochem Sci 1990; 15: 69-72.

8. Sies H, Flohe L, Zimmer G. Molecular aspects of inflammation. Berlin, Springer-Verlag, 1991.

9. Ward PA. Mechanisms of endothelial cell injury. $J$ Lab Clin Med 1991; 118: 421-425.

10. Yamazaki I, Piette LH. The mechanism of aerobic oxidase reaction catalysed by peroxidase. Biochim Biophys Acta 1963; 77: 47.

11. Sanders SP, Zweier JL, Harrison SJ, Trush MA, Rembish SJ, Liu MC. Spontaneous oxygen radical production at sites of antigen challenge in allergic subjects. Am J Respir Crit Care Med 1995; 151: 17251733.

12. Hulsmann AR, Raatgeep HR, den Hollander JC, et al. Oxidative epithelial damage produces hyperresponsiveness of human peripheral airways. Am J Respir Crit Care Med 1994; 149: 519-525.

13. Sadeghi-Hashjin G, Folkerts G, Henricks PAJ, et al. Induction of guinea pig airway hyperresponsiveness by inactivation of guanylate cyclase. Eur J Pharmacol 1996; 302: 109-115.

14. Sadeghi-Hashjin G, Folkerts G, Henricks PAJ, Muijsers RBR, Nijkamp FP. Peroxynitrite in airway disease. Clin Exp Allergy 1998; 28: 1464-1473.

15. Sadeghi-Hashjin G, Folkerts G, Henricks PAJ, et al. Peroxynitrite induces airway hyperresponsiveness in guinea pigs in vitro and in vivo. Am J Respir Crit Care Med 1996; 153: 1697-1701.

16. Chung KF. Pharmacology of airway inflammation in asthma. Lung 1990; 168: Suppl., 132-141.

17. McCord JM, Fridovich I. The reduction of cytochrome $\mathrm{C}$ oxidase by milk xanthine oxidase. $J$ Biol Chem 1968; 243: 5753-5760.

18. Babior BM. Oxygen-dependent microbial killing by phagocytes. New Engl J Med 1978; 298: 659-688.

19. Kuthan H, Ulrich V. Oxidase and oxygenase function of the microsomal cytochrome P450 monooxygenase system. Eur J Biochem 1982; 126: 583-588.

20. Fridovich I. Superoxide radical: An endogenous toxicant. Annu Rev Pharmacol Toxicol 1983; 23: 239257.

21. Sadeghi-Hashjin G, Henricks PAJ, Folkerts G, Muis T, Garssen J, Nijkamp FP. Role of the epithelial layer 
in the generation of superoxide anion by the guineapig isolated trachea. Mediators Inflam 1998; 7: 35-40.

22. Wang J-F, Komarov P, de Groot H. Luminol chemiluminescence in rat macrophages and granulocytes: the role of $\mathrm{NO}, \mathrm{O}_{2}^{-} / \mathrm{H}_{2} \mathrm{O}_{2}$, and $\mathrm{HOCl}$. Arch Biochem Biophys 1993; 304: 189-196.

23. Allen RC, Stjernholm RL, Steele RH. Evidence for the generation of an electronic excitation state(s) in human polymorphonuclear leukocytes and its participation in bacterial activity. Biochem Biophys Res Commun 1972; 47: 679-684.

24. Stevens P, Hong D. The role of myeloperoxidase and superoxide anion in the luminol- and lucigenindependent chemiluminescence of human neutrophils. Microchem J 1984; 30: 135-146.

25. Scott RB, Tan DT. Mediation of altered motility in food protein induced intestinal anaphylaxis in Hooded-Lister rat. Can J Physiol Pharmacol 1996; 74: $320-330$.
26. Crowe SE, Sestini P, Perdue PH. Allergic reactions of rat jejunal mucosa. Ion transport responses to luminal antigen and inflammatory mediators. Gastroenterol 1990; 99: 74-82.

27. Sestini $\mathrm{P}$, Bienenstock $\mathrm{J}$, Crowe $\mathrm{SE}$, et al. Ion transport in rat tracheal epithelium in vitro. Role of capsaicin-sensitive nerves in allergic reactions. Am Rev Respir Dis 1990; 141: 393-397.

28. Scott RB, Maric M. Mediation of anaphylaxisinduced jejunal circular smooth muscle contraction in rats. Dig Dis Sci 1993; 38: 396-402.

29. Miklos K, Tolnay M, Medgyesi GA. Sodium cromoglycate (Cromolyn) selectively increases the binding and phagocytosis of unsensitised target cells by rat peritoneal macrophages. Immunol Lett 1996; 52: 157-161.

30. Ezeamuzie CI, Al-Hage M. Effects of some antiasthma drugs on human eosinophil superoxide anions release and degranulation. Intl Arch Allergy Immunol 1998; 115: 162-168. 